\title{
Through Life Capability Management Perspective for Framework Development for Assessing and Measuring System Maturity, System Readiness and Capability Readiness using Architecture Frameworks
}

\author{
Mr. Abideen Tetlay \\ BA(Hons) MSc MSc(Oxon) FIAP \\ Software and Systems Engineer
}

Copyright $@$ Mr. Abideen Tetlay, Cranfield University (UK) 2010. Published and used by IEEE SoSE 2010 with permission.

\begin{abstract}
This study investigates the use of Through Life Capability Management perspective for refinement of the Conceptual Framework for Assessing and Measuring System Maturity, System Readiness and Capability Readiness using Architecture Frameworks. Metrics and measurement frameworks have no meaning if they are not used to make decisions. The importance of decision making at the architectural level is therefore discussed which is particularly pertinent for System Maturity.
\end{abstract}

Index Terms - Through Life Capability Management, Framework Assessment, System Maturity, System Readiness, Capability Readiness, Architecture Framework

\section{INTRODUCTION}

$\mathrm{T}$ ODAY'S SYSTEMS are inherently complex due to a number of reasons, such as software and systems integration between subsystems, systems of systems and networked systems of systems. This level of complexity introduces a number of challenges both during the system development programme and the overall lifecycle. This level of complexity also increases the risk in system development and system integration and implementation which is often reflected in delays in system development and/or system failure, including systems showing undeterministic behaviour once released into the real world even though they were considered to be "ready" for use [1].

During the development of a system, assessing the "maturity" of the system definition towards a successful outcome is important, as is the assessment of the "readiness" of a system to undertake roles within the real world context. Therefore, we need to be able to assess and measure, with confidence, a System's Maturity and Readiness within a development programme and overall lifecycle [1], [2], [3], [4].

The aim of the study presented in [1] was to develop a theoretical Framework for assessing and measuring System Maturity, System Readiness and Capability Readiness based on the research already undertaken by the authors [2], [3], [4]. However, in [1], although the author did provide a conceptual Framework they were unable to define a possible method for assessment and measurement which was beyond the scope of the study. Therefore, this study is a continuation of [1] with the aim of refining the Framework by providing a potential method for the assessment and measurement of System Maturity, System Readiness and Capability Readiness from a Through Life Capability Management (TLCM) perspective using Architecture Frameworks.

Manuscript received $12^{\text {th }}$ March, 2010. Corresponding author: Mr. Abideen Tetlay FIAP (e-mail: abideen.tetlay@ hotmail.co.uk).

Digital Object Identifier inserted by IEEE SoSE 2010 Conference
This paper is structured as follows. The first section provides background information regarding the conceptual Framework presented in [1]. The second section outlines the methodology used for this study followed by the main sections of the paper. Finally, the conclusions are drawn and the next stages of the research are provided in terms of recommendations for further research.

\section{BACKGROUND}

In [2], the authors introduced a new set of System Maturity Levels and a conceptual model for System Readiness and Capability Readiness, which were used as a basis for the conceptual Framework presented in [1] along with the findings from the case studies presented in the paper [2]. The author also summarised the key characteristics of System Maturity, System Readiness and Capability Readiness as depicted in Table 1 [1].

The conceptual Framework for the assessment and measurement of System Maturity is presented in Figure 1. The left hand-side of the conceptual Framework focuses on the Design and Development (System Maturity Levels 0 to 3, inclusive) for the system or product being engineered and the right hand-side concentrates on achieving verification (System Maturity Levels 4 to 6, inclusive), i.e. System Maturity [1]. The purpose of the conceptual Framework is to determine where you are in the System Development Lifecycle which determines the degree of System Maturity for the system or product currently being developed. The left hand-side of the System Development Lifecycle is less 'mature' than the right hand-side. Obviously, the further you are in the System Development Lifecycle, moving from the left to the right hand-side, the closer you are towards achieving a physical system or product and therefore achieving System Maturity [1]. 

June $22^{\text {nd }}-24^{\text {th }} 2010$, Loughborough University (UK)

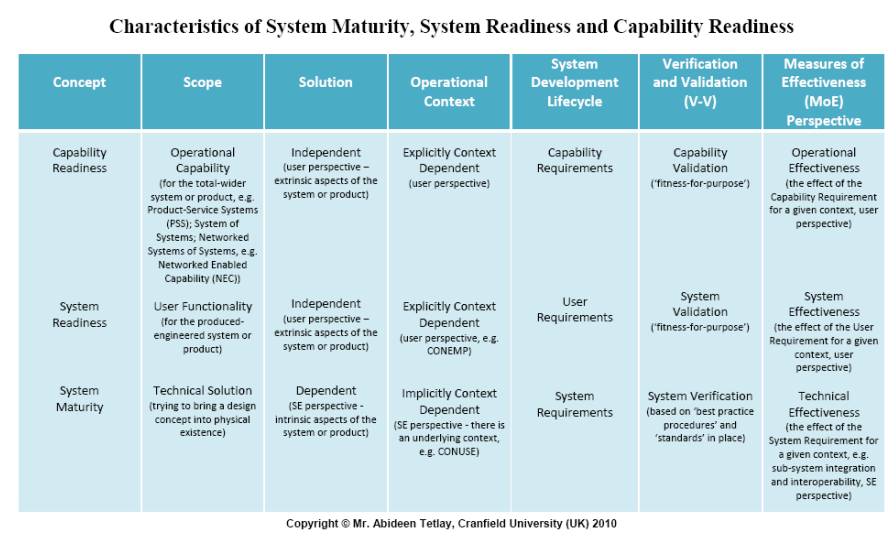

Table 1: Characteristics of System Maturity, System Readiness and Capability Readiness

The process for the assessment and measurement of System Maturity is depicted in Figure 2. The main aim of this process is to verify the System Requirements of a system or product being engineered in order to achieve System Maturity. The process should be used by system engineers and project managers to help monitor and communicate the progress of a system engineering project by assessing and measuring its System Maturity, feeding into the project planning and to enable the Systems Design Authority (SDA) and Systems IPT Lead to identify and address risks and mitigating actions in a consistent manner with confidence [1].

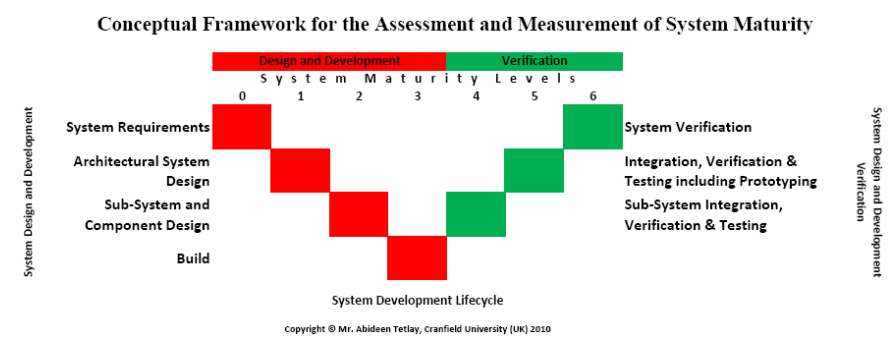

Figure 1: Conceptual Framework for the Assessment and Measurement of System Maturity

The conceptual Framework for the assessment and measurement of System Readiness is illustrated in Figure 3. System Readiness is concerned with the extrinsic aspects of the produced-engineered system with respect to how the system is expected to behave in a particular context subject to certain enablers and barriers in place [1].

An assessment is made for each operational context for the produced-engineered system taking into account the enablers and barriers currently in existence for that context. The degree of System Readiness is then determined and assessed as either achieving: 'No System Readiness' (NSR); 'Initial System Readiness' (ISR); or 'Full System Readiness' (FSR) and conceptually, the state of readiness can be thought of as being equal to either: ' 0 '; ' 1 '; or ' 2 ', respectively [1]. Detailed definitions of these terms are provided in [2]. The author has

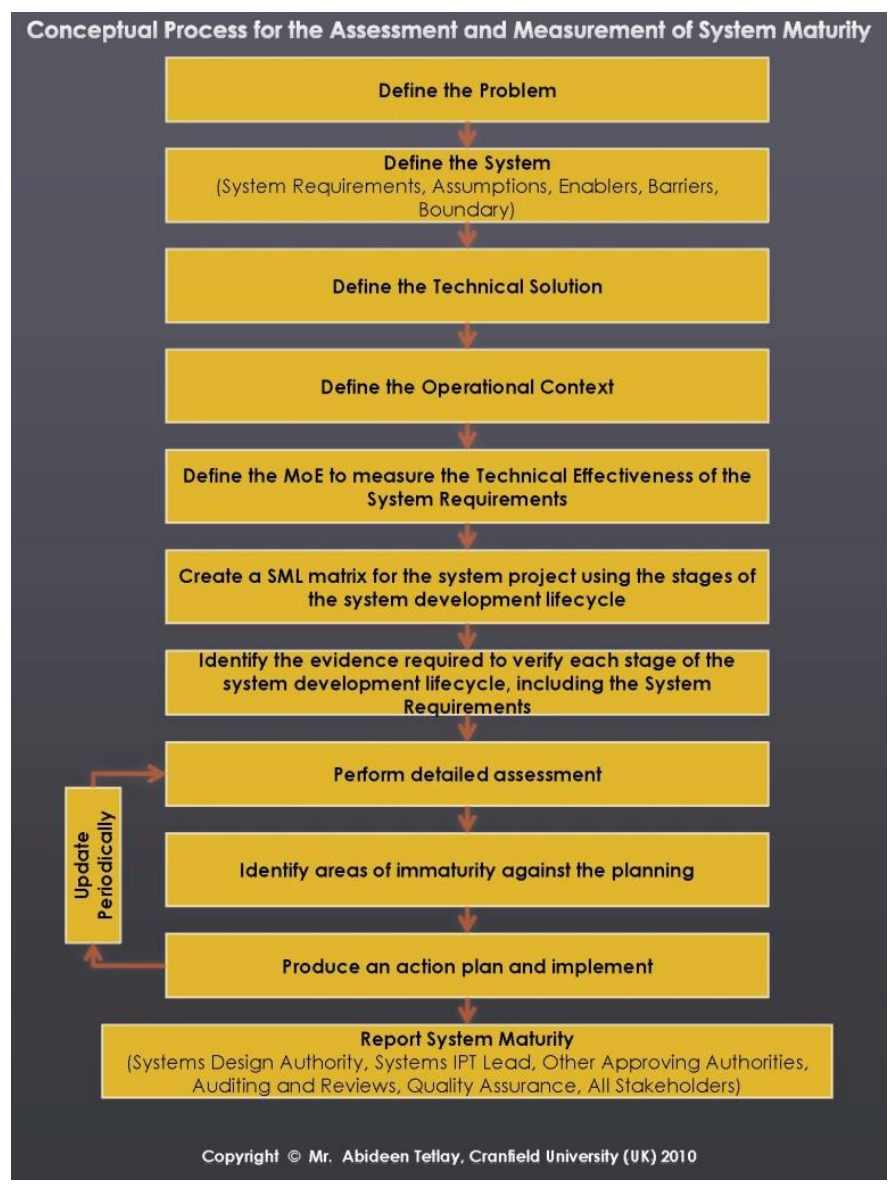

Figure 2: Conceptual Process for the Assessment and Measurement of System Maturity

Conceptual Framework for the Assessment and Measurement of System Readiness

\begin{tabular}{|c|c|c|}
\hline \multicolumn{3}{|c|}{ Extrinsic Aspects of the System or Product } \\
\hline Context & Enablers & Barriers \\
$\begin{array}{c}\text { Travelling through the } \\
\text { desert from Marrakech to } \\
\text { Cassablanca in a newly } \\
\text { engineered Hybrid motor } \\
\text { vehicle during May 2010 }\end{array}$ & $\begin{array}{c}\text { Infrastructure (petrol and } \\
\text { gas refuelling stations), } \\
\text { Availability of trained } \\
\text { 'Hybrid' drivers, Off-Road } \\
\text { tyres for desert conditions }\end{array}$ & $\begin{array}{c}\text { Extreme Weather } \\
\text { Conditions (atmospheric } \\
\text { pressure, temperature, } \\
\text { humidity), Security, Safety, } \\
\text { On-Road tyres }\end{array}$ \\
\hline $\begin{array}{c}\text { Travelling from London to } \\
\text { Edinburgh in a newly } \\
\text { engineered Hybrid motor } \\
\text { vehicle during February } \\
2010\end{array}$ & $\begin{array}{c}\text { Infrastructure (motorways, } \\
\text { petrol and gas refuelling } \\
\text { stations), Availability of } \\
\text { trained 'Hybrid' drivers, } \\
\text { Winter or All season tyres }\end{array}$ & $\begin{array}{c}\text { Extreme Weather } \\
\text { Conditions (snow, ice), } \\
\text { Safety, Wet tyres }\end{array}$ \\
\hline $\begin{array}{c}\text { Travelling from London to } \\
\text { Edinburgh in a newly } \\
\text { engineered Hybrid motor } \\
\text { vehicle during July 2010 }\end{array}$ & $\begin{array}{c}\text { Infrastructure (motorways, } \\
\text { petrol and gas refuelling } \\
\text { stations), Availability of } \\
\text { trained 'Hybrid' drivers }\end{array}$ & Extreme Weather \\
Conditions, Safety
\end{tabular}

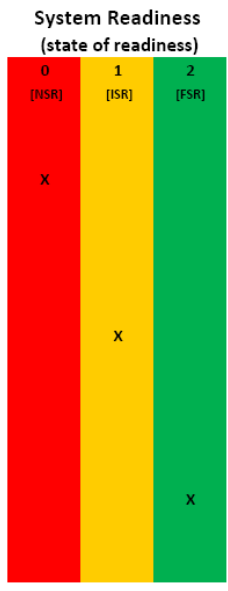

Figure 3: Conceptual Framework for the Assessment and Measurement of System Readiness

provided three examples illustrating the three states of readiness as shown in Figure 3 [1].

The process for the assessment and measurement of System Readiness is depicted in Figure 4. 


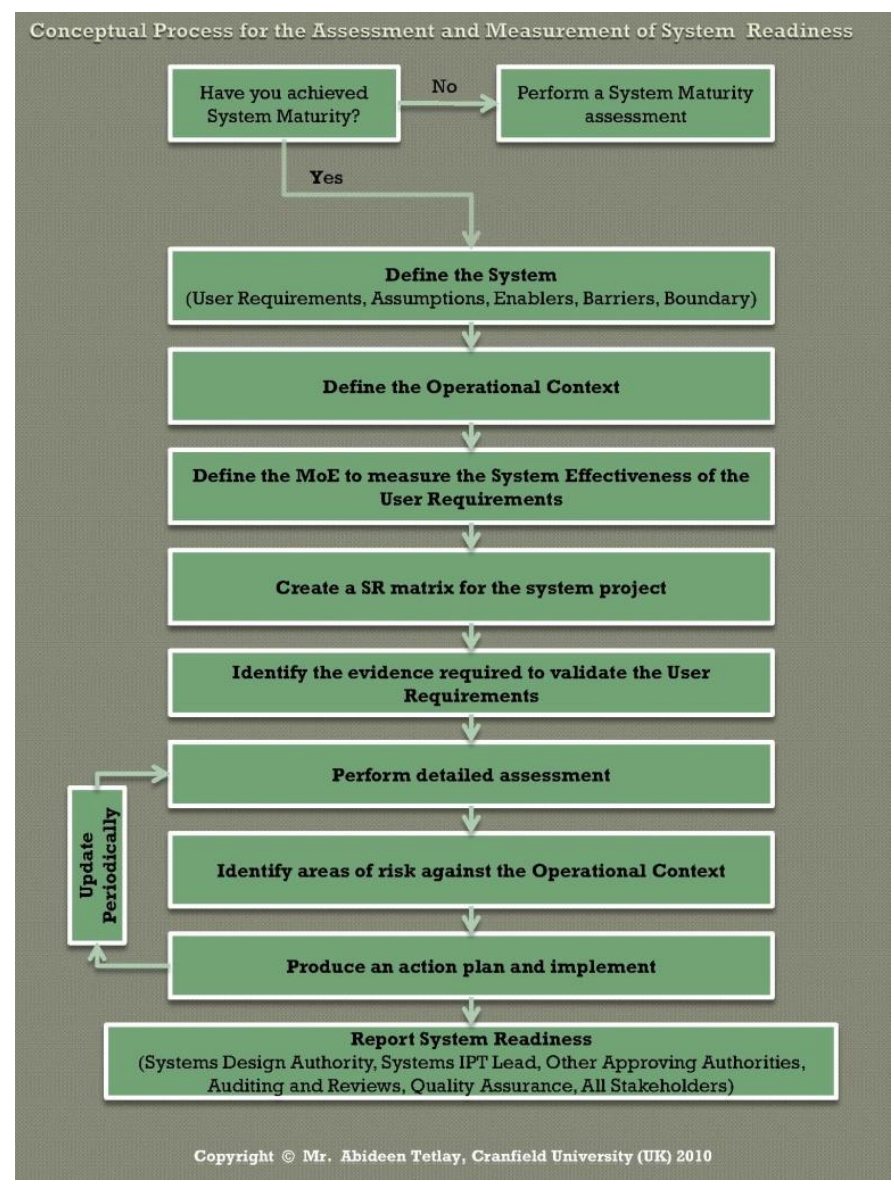

Figure 4: Conceptual Process for the Assessment and Measurement of System Readiness

It is important to note that you first need to perform a System Maturity assessment and actually achieve System Maturity, i.e. the physical system must physically exist and be developed based on best practice procedures and standards in place and be fully mature and tested as mentioned in [2] and before a System Readiness assessment can take place. The main aim of this process is to validate the User Requirements for a system being engineered in order to achieve System Readiness [1].

The conceptual Framework for the assessment and measurement of Capability Readiness is illustrated in Figure 5. Capability Readiness is concerned with the extrinsic aspects of the system with respect to how the system is expected to behave in a 'total-wider' system for a particular context subject to certain DLoD and enablers and barriers in place, rather than just focusing on the produced-engineered system for a particular context which is System Readiness. An assessment is made for each operational context for the system in question taking into account the DLoD and the enablers and barriers currently in existence for that context. An assessment for Capability Readiness will always take into account the DLoD in order to identify and mitigate risks across the DLoD. The degree of Capability Readiness is then determined and assessed as either achieving: 'No Capability Readiness' (NCR); 'Initial Capability Readiness' (ICR); or 'Full
Capability Readiness' (FCR) and conceptually, the state of operational capability readiness can be thought of as being equal to either: ' 0 '; ' 1 '; or ' 2 ', respectively [1]. Detailed definitions of these terms are provided in [2]. The author has provided three examples illustrating the three states of operational capability readiness in Figure 5 [1].

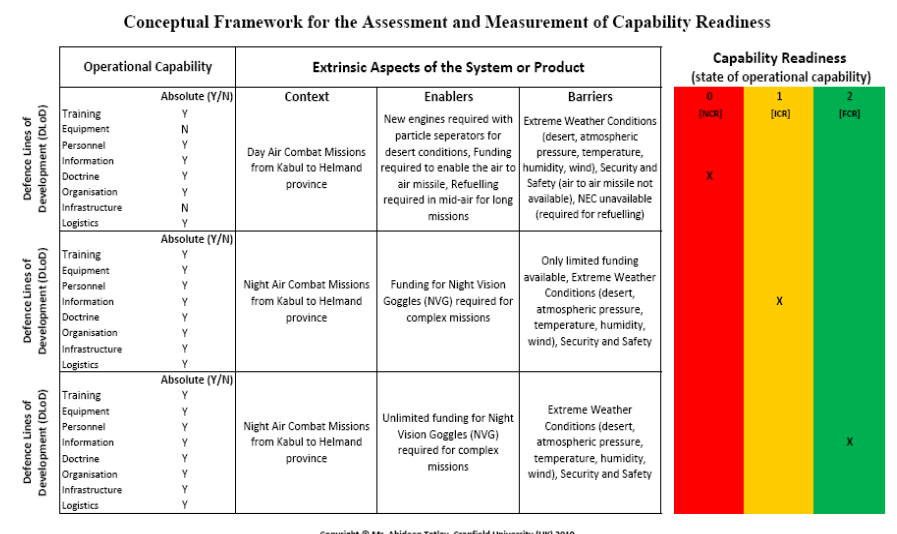

Figure 5: Conceptual Framework for the Assessment and Measurement of Capability Readiness

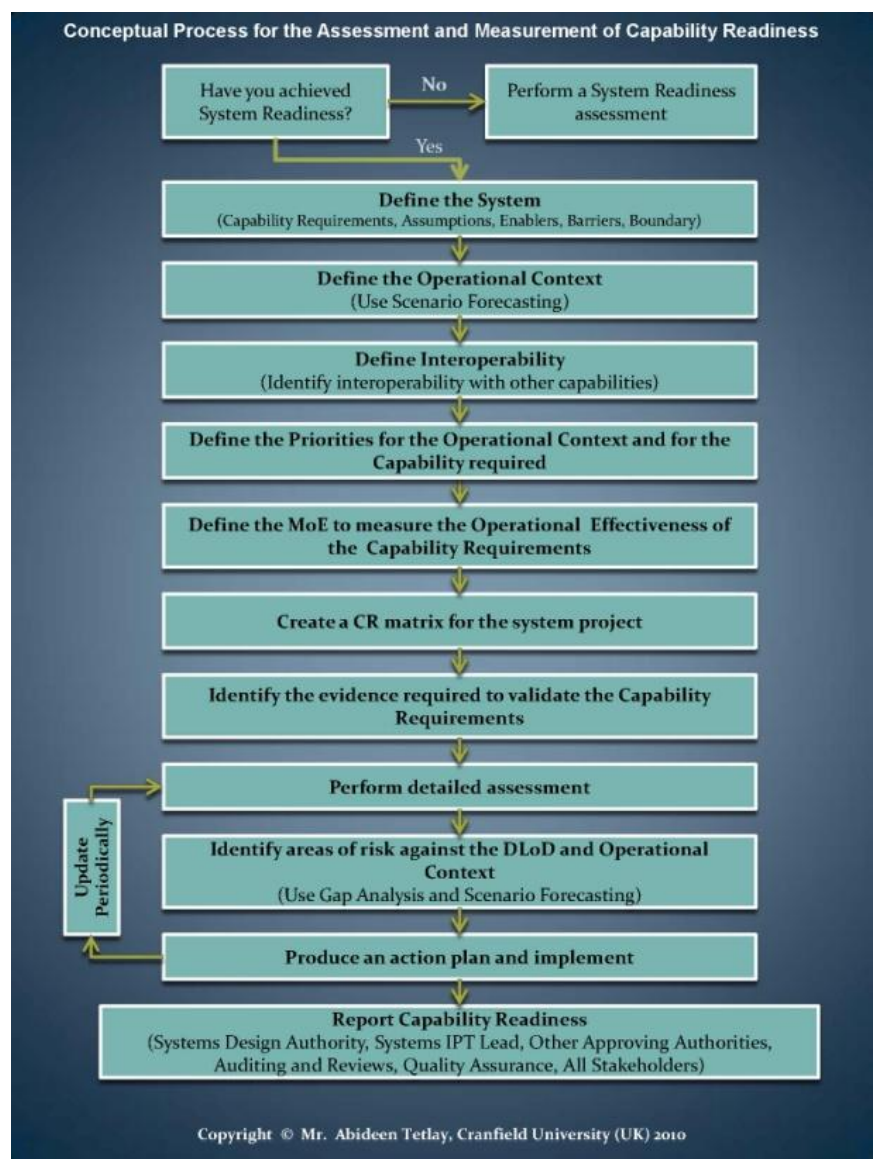

Figure 6: Conceptual Process for the Assessment and Measurement of Capability Readiness

The process for the assessment and measurement of Capability Readiness is depicted in Figure 6. It is important to note that you first need to perform a System Readiness assessment and 
actually achieve System Readiness, i.e. the physical system must physically exist and be "ready" for use for a particular context, i.e. the 'Fitness for Purpose' question. Capability Readiness extends this notion of readiness and asks the question: Is the system ready for use as a part of a 'totalwider' system? The main aim of this process is to validate the Capability Requirements for a system operating in a 'totalwider' system in order to achieve Capability Readiness.

\section{METhODOLOGY}

The following four questions were specifically devised in relation to Figure 7 and subsequently used for the extensive TLCM literature review which followed in order to provide answers to the questions:

1) Why is the Operational Capability perspective important in Systems Engineering?

2) What is the relevance of the Through Life Capability Management (TLCM) perspective?

3) What is the objective for an Assessment and Measurement of Operational Capability?

4) What are the issues in determining the degree of Capability Readiness for Systems and Networked Systems of Systems?

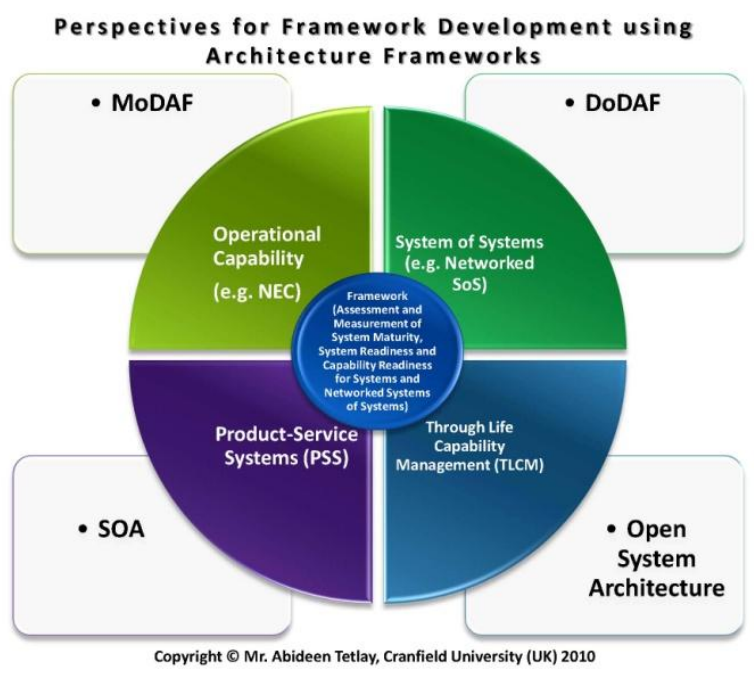

Figure 7: Perspectives for Framework Development using Architecture Frameworks

\section{WHY IS THE OPERATIONAL CAPABILITY PERSPECTIVE IMPORTANT IN SYSTEMS ENGINEERING?}

In [4], the authors explained why there needs to be an assessment of the operational capability of the system. This section will extend that argument from the results of the literature review. In [4], the authors stated that the concept of Readiness, i.e. System Readiness may be further expanded and related to Capability, i.e. Capability Readiness to assess when a system is 'Fit-for-Purpose' for a particular operational capability context [4], [3]. According to [5], the desired capability can only be achieved if the activities within all eight Defence Lines of Development (DLoD) are at an appropriately matched level of readiness or maturity. The DLoD are concerned with operational readiness, i.e. development to a level appropriate for deployment (e.g. training refers to the training of military personnel such that the appropriate people are trained to an appropriate level of preparedness for deployment). This emphasis on capability also requires greater care with how the constituents of the System of Systems (SoS) which interact to realise operational capability are integrated and their collective performance (or emergent properties) is predicted [6]. In order to provide reliable and sustainable military capability, fast paced changes must be conducted without halting the operation of a capability [7]. It is important to note the importance of capability in architecture frameworks, for example, the MoDAF architectural framework has incorporated the concept of capability as one of its core features [8].

With respect to Framework development, according to [8], the concept of a Scenario has long been utilized in military procurement as a means of evaluating capability in an operational context. This requires an evaluation method that not only allows a verification of resource implementations against specifications, but also provides a validation of the abstract system being 'fit for use'. One evaluation methodology examines the use of Measures of Effectiveness $(\mathrm{MoE})$ and Measures of Performance (MoP) as a basis for evaluation. This evaluation is performed utilizing scenarios, rather than attempting to evaluate specific architectures directly. Scenarios are often expressed in the form of Use Cases [8]. According to [8], NATO defines a scenario as a description of the area, the environment, means, objectives, and events related to a conflict or a crisis during a specified time frame suited for satisfactory study objectives and the problem. A scenario allows evaluation of a particular capability to be guided towards situations that are likely to occur in operation. The purpose of scenarios is to ensure that the analysis is informed. The implication of this is that whilst a scenario can guide the evaluation process an evaluation may not necessarily cover all possible uses of a capability. Therefore, it is essential that scenarios are well constructed and thought-out so they cover all relevant conditions that a capability is likely to encounter. In [1], the author has already suggested the use of scenarios for the assessment and measurement of Capability Readiness, but these findings will now aid in the planning and construction of the scenarios in the form of heuristics.

\section{WHAT IS THE RELEVANCE OF THE THROUGH LIFE CAPABILITY MANAGEMENT (TLCM) PERSPECTIVE?}

The official UK MoD definition of TLCM is: an approach to the acquisition and in-service management of military capability in which every aspect of new and existing military capability is planned and managed coherently across all Defence Lines of Development (DLoD) from cradle to grave [5]. Capabilities must be designed to co-evolve with their environment and the evolution must be supported over a very 
long time. Decision making needs to take a long-term perspective [5].

TLCM and the realisation of Networked Enabled Capability (NEC) cannot be considered independently, in fact, they are intrinsically linked [5]. NEC is a concept of system architecture [9]. NEC is designed to provide information superiority and reduced decision times leading to faster responses [10]. In describing NEC, the UK Ministry of Defence (MoD) Joint Service Publication (JSP) 777 [2005b] states: Networked Enabled Capability offers decisive advantage through the timely provision and exploitation of information and intelligence to enable effective decision making and agile actions [11]. NEC is described as a complex socio-technical capability that should be considered holistically across all DLoD [11]. In the early system definition phases of a project, strategic vision and user needs must be captured and accurately translated into requirements, establishing the operational context for system development [11]. This notion of capturing requirements for the operational context has already been defined in the Framework as Capability Requirements [1]. According to [12], the network enabled architecture will need to integrate systems of systems in a flexible manner, identifying the assets that provide the functionality and characteristics of the task. For NEC, large-scale system and integration of systems of systems need to cope with fast paced changes and operate in unknown and dynamic environments. The challenge for architectures in NEC is to express known characteristics alongside unknown or variable attributes, using monitoring to evaluate an architecture through its lifetime in unknown and variable situations [12]. In the future NEC battlefield, the SOA architecture enables the integration of resources in a known and visible way. Measurement of the properties of individual resources can be combined to assess the functional and non-functional properties of the integrated system of systems. Using service descriptions to represent the functional responsibilities of the resource, then the behaviour of the architecture can be assessed using the integration of services. The service descriptions include functional description and the Quality of Service (QoS) attributes, such as availability, accessibility, integrity, reliability, security, maintainability and resilience to name a few of the characteristics. These QoS attributes are important measures that need to be monitored in use, but also need to be known for mission planning and acquisition [12].

Capability Based Planning has gained momentum in recent years as a way for organizations to make resource decisions from a "top-down" perspective. Recent use of Process Sequence Model (PSM) diagrams highlights greater use of architectures in decision making [13]. By focusing on capability, and by taking a through-life perspective, customers can better assess how they can meet their operational needs, and can better understand and balance acquisition and operational/support costs. It is recognised that the decisionmaking necessary to plan and realise integrated capabilities will require greater collaboration than previously [6].
With respect to Framework development, QoS attributes should be introduced to the Framework as a way of using these attributes to assess and measure the non-functional aspects of a system which tend not to receive the same level of treatment as functional requirements, but are just as important. Quality attributes can be defined and decomposed so that they can be measured and prepared for assessment. The information obtained for quality attributes can then be input into a Multi-Criteria Decision Making (MCDM) technique to provide assessment results [15]. A good system is one which meets the needs of its users. To do this it must fulfil nonfunctional requirements such as being useable, reliable, flexible, affordable and available [15]. The authors have already implied this in their previous research [3] but should now be formally considered for the Framework. For Software-Intensive Systems, the ISO/IEC Software Engineering Product Quality Standard Model could be used to derive the QoS attributes for the internal and external quality aspects of a system. The authors have provided a simple example to illustrate the potential use of QoS attributes using ARM (Availability, Reliability and Maintainability) as depicted in Figure 8. System Maturity is associated with maintainability and reliability. This is based on the premise that you first need to maintain a system before it can be made reliable and once you have a reliable system only then can it be made available for operational use and this is associated with System Readiness. Once a system is available for use, it needs to be sustainable over the course of time and this is associated with Capability Readiness. Therefore, sustainability is a function of maintainability, reliability and availability in its simplest form.

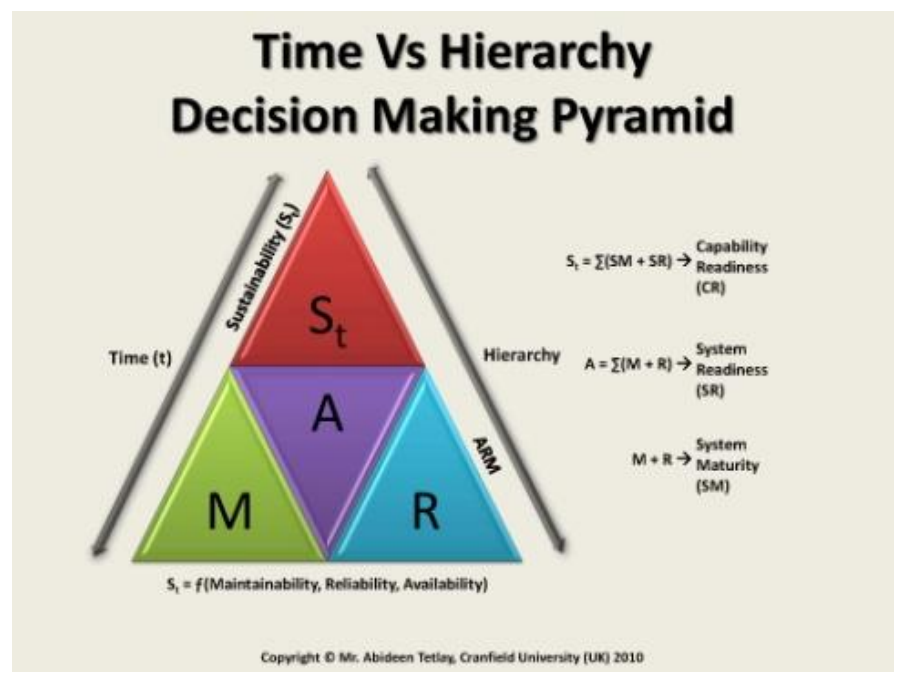

Figure 8: Time Vs Hierarchy Decision Making Pyramid In previous research [3] the authors have already discussed the relationship between Capability and Product-Service Systems (PSS) and the need for the assessment of Capability Readiness for PSS. They suggested that this assessment is essential to determine whether or not the elements of capability for PSS are in place and maintained for the successful delivery of a sustainable PSS [1], [3]. According to [14], good systems 
engineering (particularly in pursuit of sustainability) can help design out unnecessary complexity, but in general, a flexible, precise, agile, and long-range capability, will be a complex one. As we face a more diverse range of threats we will need to ensure that our capability is flexible, adaptable and capable of upgrade. We now expect our platforms to endure in-service for long periods, supported by both regular and operationspecific upgrades. At the same time, technology, particularly in electronics, continues to evolve rapidly. This may imply that the most significant opportunities for upgrading capability will be identified and resolved at a) the systems of systems, or b) the partial systems and sub-systems level, rather than being driven by fundamental modifications to a platform architecture. The innovation and ability to exploit technology development and improve other aspects of military capability may increasingly reside at these lower, partial system and subsystem, levels [14].

\section{WHAT IS THE OBJECTIVE FOR AN ASSESSMENT AND MEASUREMENT OF OPERATIONAL CAPABILITY?}

A critical factor, which will determine whether the planning is successful, is how to measure a military capability. If wrong measures are adopted, no matter how robust the process is, the end result will still be disastrous. However, measuring capability is very difficult and our current knowledge in this area is dreadfully limited [5]. The ultimate goal (in assessment) is the ability to quantitatively evaluate and tradeoff multiple quality attributes to arrive at a better overall system [15]. Systems engineering capability is central to understanding whether the system will operate as you want it to, when delivered, and as it evolves through life; it may not always be possible to tell this simply by independent testing. This applies both for initial purchase and for support and upgrades. Having reliable access to this capability within the UK, particularly for Urgent Operational Requirements (UOR), is generally a high priority. We need technology which will enhance enabling processes to the delivery of capability and enhance decision making [14]. According to [5], when evaluating options, the high uncertainty of the external environment means that flexibility and adaptability must enter this decision process with a higher weighting than has traditionally been the case. A further change to the basis for decision-making concerns the balance of efficiency and agility. Solutions with greater opportunity to adapt in an agile fashion will likely provide the more cost-effective approach over the long-term. Systems that cannot readily adapt to a changing environment do not survive. There is a clear need for the development of appropriate metrics for TLCM.

With respect to Framework development, once the QoS attributes have been derived or determined they should be placed in priority order depending on the requirements, context and system of use.

\section{WHAT ARE THE ISSUES IN DETERMINING THE DEGREE OF CAPABILITY READINESS FOR SYSTEMS AND NETWORKED SYSTEMS OF SYSTEMS?}

According to [16], metrics and measurement frameworks have no meaning if they are not used to make decisions. The practical reality is that managers have to make decisions with imperfect information. A metric can be considered any observation that can reduce the uncertainty of the practical environment. Three themes for decision makers:

(1) Tying decisions to the right problem;

(2) Being confident in making decisions with minimal or imperfect information; and

(3) Identifying leading indicators for successful business transformation [16]. Hubbard (2007) identifies five questions decision makers should consider before measuring, seen as follows [16]:

1. What is the decision this [measurement] is supposed to support?

2. What really is the thing being measured?

3. Why does this thing matter to the decision being asked?

4. What do you know about it now?

5 . What is the value to measuring it further?

Metrics are a system of measurement through which the merits of an entity can be assessed and measures may contribute to a metric as a set of quantitative values within the system [17].

With respect to Framework development, it may be prudent to incorporate Hubbard (2007) five questions as pre-requisites for Framework assessment. In order to cover the complete view of a system the Zachman (1987) framework could also be adopted for the Framework. Zachman's framework for information systems architecture is usually depicted with a matrix of 6 rows and 5 columns. The columns, labelled Data/What, Function/How, Network/Where, People/Who, Time/When and Motivation/Why, can be understood as architecture concerns with respect to the enterprise of interest in IEEE 1471 terms. The rows, labelled Planner, Owner, Designer, Builder, Programmer, and User, can be understood as stakeholders. Each row is called a stakeholder view or role perspective by Zachman and is intended to be a complete view of the system (as is also required in IEEE 1471). Each cell of the matrix depicts a perspective, or way of viewing the subject [18]. From sound operational architecture, the engineer can begin to design solution systems and analyze them to verify that their performance is sufficiently robust [19].

\section{CONCLUSIONS}

This study has proposed a number of key recommendations to the conceptual Framework presented in [1]. This includes planning and construction of the scenarios in the form of heuristics; the use of Quality of Service (QoS) attributes to assess and measure the non-functional aspects of a system; to incorporate Hubbard (2007) five questions as pre-requisites for Framework assessment; and in order to cover the complete view of a system the Zachman (1987) framework could also be adopted for the Framework. 


\section{FURTHER RESEARCH}

Further research is required to further develop the Framework from a Product-Service Systems (PSS) perspective using Architecture Frameworks. This is part of the on-going research. The next and final stage of the research is to 'industrialise' the Framework for practitioner use to make it 'fit-for-purpose' through industry workshops in order to refine the Framework, as appropriate, for wider use and applicability and for validation of the Framework.

\section{ACKNOWLEDGMENTS}

The author would like to thank the UK Engineering and Physical Sciences Research Council (EPSRC) and BAE Systems for jointly funding the research project.

\section{REFERENCES}

[1] Tetlay, A. (2010), Conceptual Framework for Assessing and Measuring System Maturity, System Readiness and Capability Readiness, International Council on Systems Engineering (INCOSE) $7^{\text {th }}$ European Systems Engineering Conference (EuSEC 2010), May $23^{\text {rd }}-26^{\text {th }} 2010$, Stockholm, Sweden - Accepted

[2] Tetlay, A. and John, P. (2010), Clarifying the Concepts of System Maturity, System Readiness and Capability Readiness through Case $\underline{\text { Studies, }} 8^{\text {th }}$ Annual Conference on Systems Engineering Research (CSER 2010), March $17^{\text {th }}-19^{\text {th }} 2010$, Hoboken, New Jersey, United States

[3] Tetlay, A. and John, P. (2009), Capability Readiness for ProductService Systems, $7^{\text {th }}$ International Conference on Manufacturing Research (ICMR09), September $8^{\text {th }}-10^{\text {th }} 2009$, Warwick University (UK)

[4] Tetlay, A. and John, P. (2009), Determining the Lines of System Maturity, System Readiness and Capability Readiness in the System Development Lifecycle, $7^{\text {th }}$ Annual Conference on Systems Engineering Research (CSER09), April $20^{\text {th }}-23^{\text {rd }} 2009$, Loughborough University (UK), ISBN: 978-0-9562440-0-0

[5] Yue, Y. and Henshaw, M. (2009), "An Holistic View of UK Military Capability Development", Defense \& Security Analysis, Vol. 25, No. 1, pp. 53-67, DOI 10.1080/14751790902749900

[6] Harding, A., Mollett, J. and Touchin, M. (2009), "A structured approach to planning and managing systems engineering capability evolution in a complex through-life business space", in: $7^{\text {th }}$ Annual Conference on Systems Engineering Research 2009 (CSER 2009), 20 $0^{\text {th }}-23^{\text {rd }}$ April 2009, Loughborough University (UK)

[7] Liu, L., Russell, D. et al. (2009), "Delivering Sustainable Capability on Evolutionary Service-oriented Architecture", in: 2009 IEEE International Symposium on Object/Component/Service-Oriented RealTime Distributed Computing, 2009, 1555-0885/09, DOI 10.1109/ISORC.2009.9

[8] Looker, N., Webster, D. et al. (2008), "Scenario Based Evaluation", in: $11^{\text {th }}$ IEEE Symposium on Object Oriented Real-Time Distributed Computing (ISORC), 2008, 978-0-7695-3132-8/08, DOI 10.1109/ISORC.2008.56

[9] Kątcki, A. (2009), "Polish Automated System for Air Forces - Polish Way to Introduce Network Enabled Capability"

[10] Goode, R. et al, (2006), "IPv6 for Coalition Network Enabled Capability", in: MILCOM 2006 Unclassified Paper Number 399

[11] Blair, C. D. et al. (2007), "Communicating Strategic Intent with Systemigrams: Application to the Network-Enabled Challenge", Systems Engineering, Vol. 10, No. 4, pp. 309-322

[12] Russell, D. et al. (2008), "Service-Oriented Integration of Systems for Military Capability", in: $11^{\text {th }}$ IEEE Symposium on Object Oriented RealTime Distributed Computing (ISORC), 978-0-7695-3132-8/08, DOI 10.1109/ISORC.2008.45

[13] Mastro, P. C. et al. (2009), "Enterprise Architecture Support for Capability Based Assessments", in: $7^{\text {th }}$ Annual Conference on Systems Engineering Research 2009 (CSER 2009), 20 $0^{\text {th }}-23^{\text {rd }}$ April 2009, Loughborough University (UK)
[14] UK MoD Defence Industrial Strategy, Defence White Paper, December 2005, Cm 6697, pp. 59-67 and pp. 122-124, available at: http://www.mod.uk/nr/rdonlyres/f530ed6c-f80c-4f24-84380b587cc4bf4d/0/def_industrial_strategy_wp_cm6697.pdf $\left(\right.$ accessed $7^{\text {th }}$ December 2009)

[15] Purewal, K. et al. (2009), "Quantitative Assessment of Quality Attributes in Systems Architecture using Evidential Reasoning", in: $7^{\text {th }}$ Annual Conference on Systems Engineering Research 2009 (CSER 2009), $20^{\text {th }}-23^{\text {rd }}$ April 2009, Loughborough University (UK)

[16] Blackburn, C. and Valerdi, R. (2009), "Navigating Metrics Landscape: An Introductory Literature Guide to Metric Selection, Implementation, \& Decision Making", in: $7^{\text {th }}$ Annual Conference on Systems Engineering Research 2009 (CSER 2009), 20 $0^{\text {th }}-23^{\text {rd }}$ April 2009, Loughborough University (UK)

[17] Venters, C. C. et al. (2009), "A Scenario-Based Architecture Evaluation Framework for Networked Enabled Capability", in: $200933^{\text {rd }}$ Annual IEEE International Computer Software and Applications Conference, 0730-3157/09, DOI 10.1109/COMPSAC.2009.108

[18] Emery, D. and Hilliard, R. (2009), "Every Architecture Description Needs a Framework: Expressing Architecture Frameworks Using ISO/IEC 42010", 978-1-4244-4985-9/09

[19] Baumgarten, E. (2008), "Dynamic DoDAF Power Tools", MILCOM 2008:2176, 978-1-4244-2677-5/08

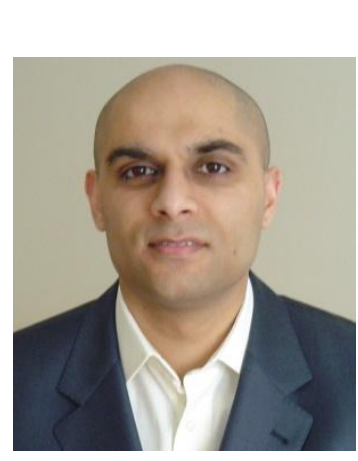

\section{BIOGRAPHY}

Abideen Tetlay is currently working as a Systems Engineer for the Raytheon Company based in the UK covering the Systems Engineering Lifecycle to primarily support a major new Command and Control (C2) programme for the UK Ministry of Defence $(\mathrm{MoD})$. He has previously spent 10 years working as a professional Software and Database Engineer reaching Consultant level. He has worked for the following UK based companies: K3 Business Technology Group; Bidwells Property Consultants; Lloyds Banking Group; and the Royal Society of Chemistry. Before embarking on an IT career, he first obtained a Bachelor's degree BA (Hons) Business Administration from the University of Bedfordshire (UK). This was followed by a Master's degree MSc Information Technology (Management Information Systems) from Cranfield University (UK) and then he moved into the IT field. Several years later, he gained another Master's degree MSc Software Engineering from St Cross College, University of Oxford (UK) which was sponsored by Lloyds Banking Group. $\mathrm{He}$ is a Fellow of the Institution of Analysts and Programmers (FIAP). 